\title{
On an exceptional sample of wooden crystallographic models from the collection of minerals at the École des Mines de Saint-Étienne (France): description, history, digitalization, duplication
}

\author{
Jean Rieu ${ }^{1}$, Victor Beley ${ }^{2,3}$, and Bernard Guy ${ }^{1}$ \\ ${ }^{1}$ École des Mines de Saint-Étienne, Institut Mines-Télécom, Univ Lyon, CNRS, Univ Jean Monnet, \\ Univ Lumière Lyon 2, Univ Jean Moulin Lyon 3, ENS Lyon, ENTPE, ENSA Lyon, \\ UMR 5600 EVS, Centre SPIN, 42023 Saint-Étienne, France \\ ${ }^{2}$ ENSA Paris-La Villette, ESTP Paris, 94230 Cachan, France \\ ${ }^{3}$ School of Engineering, Aalto University, 02150 Espoo, Finland
}

Correspondence: Bernard Guy (guy@emse.fr)

Received: 7 September 2021 - Revised: 7 December 2021 - Accepted: 14 December 2021 - Published: 1 February 2022

\begin{abstract}
The École des Mines de Saint-Étienne possesses an important collection of wooden and terracotta crystallographic models (several hundreds). During the 2000s, enhancement and rehabilitation action was undertaken. Several series of Krantz models were identified by the logos and linked to catalogs. The relation of these models to the important work of Paul Heinrich von Groth, in cooperation with the Krantz company, is highlighted. An exceptional element was discovered: a polyhedron with 170 facets, from the cubic system. After a short description of the model, we report on the digitalization work, followed by a description of two duplication methods: 3D printing and precision lost-wax vacuum casting.
\end{abstract}

\section{Introduction}

The École des Mines de Saint-Étienne owns a mineral collection with great patrimonial value. There are few universities that continue to use crystallographic models for teaching crystallography, and museums do not enhance their collections when they have them. In addition to the thousands of pieces from nature, there is a collection of more than 400 wooden crystallographic models (Fig. 1) and about 100 pieces of terracotta models (Fig. 2). There are several crystal model collections around the world, but in France, our collection is one of the most important among those in Strasbourg (Musée de Minéralogie), Paris (École des Mines, Muséum National d'Histoire Naturelle), Lyon (Musée des Confluences) and Clermont-Ferrand (Université Clermont Auvergne). Until the 1970s, many students used these models as visualization aids in crystal morphology courses.

In 1993, collections that were no longer of educational interest were stored in the reserves of the École des Mines and remained there until 2009. It was under the leadership of Philippe Jamet, director of the school, that their safeguarding was undertaken. Subsequently, a working group was set up with competent mineralogists and a few volunteers to restore the entire collection. During this effort, the crystallographic models were assessed; classified; and made accessible in a contemporary, user-friendly format. They have been sorted according to the seven crystal systems.

After a reminder of the history of the crystallographic models, we will give a short description of the ones in the collection of the École des Mines and an account of the way we have managed them and connected them with the old catalogs. The collection includes an element of exceptional quality by its large number of facets, its scientific interest and the technical prowess it represented at the time of its fabrication. It is a piece of the cubic system with 170 facets and that bears the number 416. It is the last item in the Krantz 416 set, catalog 6b, third edition (Groth, 1905a), which can be found in the Virtual Museum of the History of Mineral- 
(a)

(b)

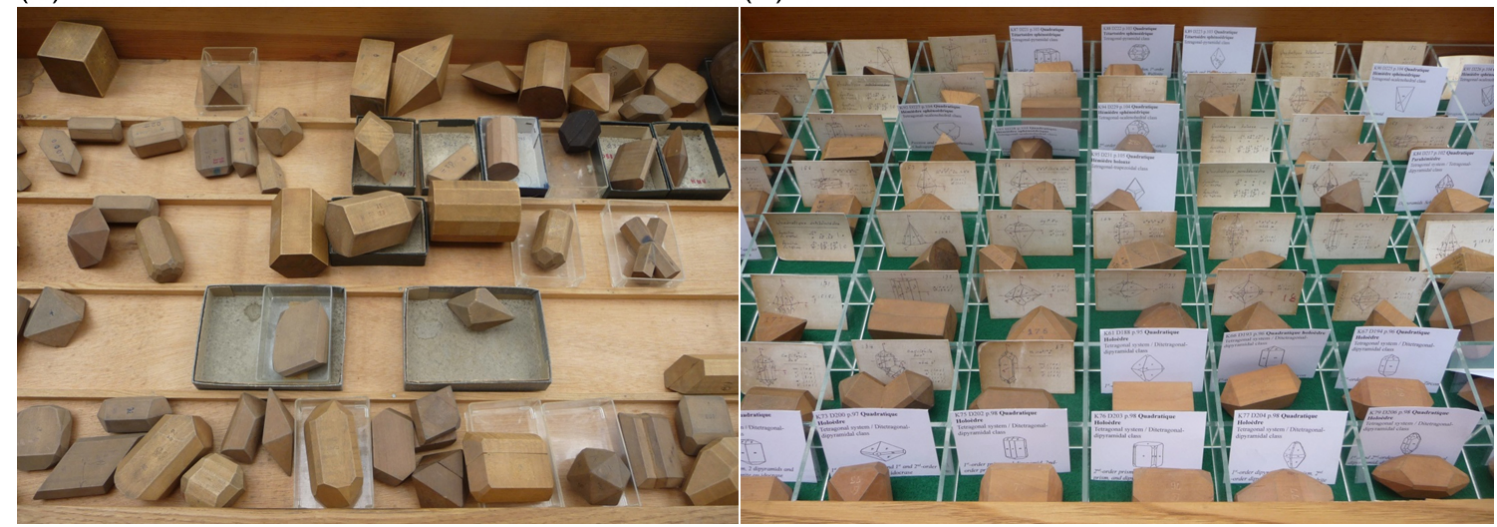

Figure 1. Some crystallographic wooden models before (a) and after (b) restoration. Dimensions of models max $70 \mathrm{~mm}$.

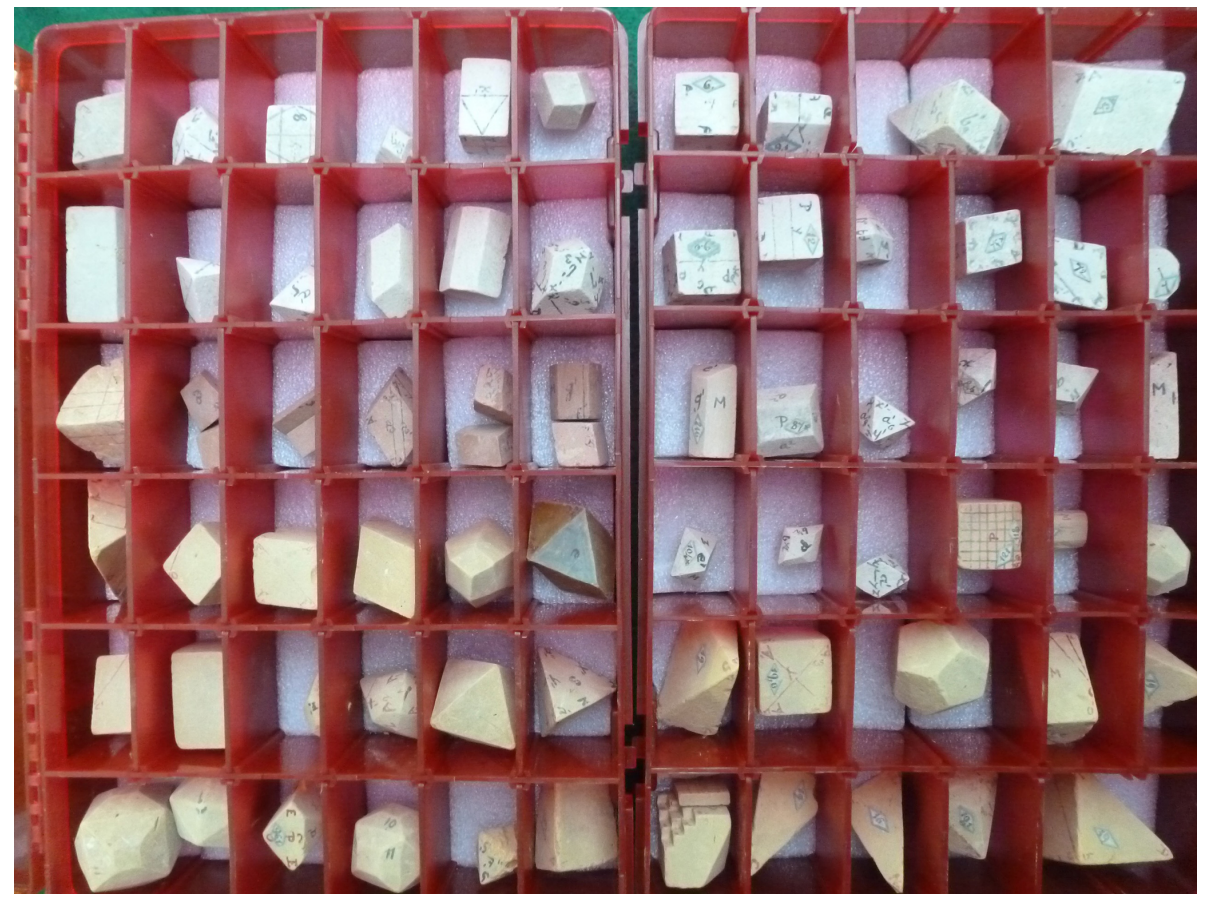

Figure 2. Terracotta models. Dimensions of models max $50 \mathrm{~mm}$.

ogy (https://mineralogy.eu, last access: 10 November 2021 ). A detailed description of this piece will be given. Our first aim was to analyze its complexity and try to imagine how it was produced when manufacturers had only goniometers and milling machine tools. Nowadays, few people would be able to manufacture it with these elementary devices. It is one of the reasons why we made copies by modern means of digital machining and precision art foundry (lost-wax vacuum casting). We hope that this paper will allow us to discover some similar models. Our goal is thus to describe model 416 while providing some more general history on model collections, which are part of a revival in the world of interest in collections that has been taking place since the early 1990s (Johan Kjellman, personal communication, 2021).

\section{Crystallographic models}

\subsection{History of crystallographic models}

Jean-Baptiste Romé de l'Isle (1736-1790) was interested in the geometric shapes of crystals with their primitive shapes and truncations in his crystallography works of 1772 and 1783. He originated the idea, thanks to a goniometer, of making terracotta models for teaching crystallography (Romé de l'Isle, 1783). 
At the same time, René Just Haüy (1743-1822) defined the foundations of crystallography, as early as 1784, in his Essai d'une théorie sur la structure des cristaux (Haüy, 1784), followed by his Exposition abrégée de la Théorie de la Structure des Cristaux (Haüy, 1792), in which he linked the shape of crystals to the elementary structure of their basic elements (integral molecules that would become, in 1840, the mesh). He originated the idea of making wooden models, which were produced by Claude Pleuvin and Louis Beloeuf (Muséum La Rochelle, France) at the beginning of the 19th century. In addition to wooden and terracotta models, some collections of glass, cardboard, wire or solid metal models can be found around the world. Much more information on the early crystal model makers can be found in the papers of Wilson and Kjellman (2015) and Kjellman et al. (2020).

The Teylers Museum in Haarlem (the Netherlands) has a collection of about 700 pieces purchased by its first curator Martinus Van Marum (1750-1837), who knew the two above-mentioned French scientists well (Touret, 1991). Nowadays, more and more crystal model collections are surfacing, and thus sources for new research are becoming available, e.g., Tandy (1998) (Natural History Museum, London), Insley (2012) (National Museum of Scotland) and Kjellman et al. (2020) (Werner collections, Freiberg).

The company Krantz, in Bonn, has been making wooden models since 1880. It began under the leadership of the professor of mineralogy Paul Heinrich von Groth (1843-1927), who was also the initiator of the Strasbourg collections when Alsace was attached to Germany in 1870 . From 1874 to 1918, he had more than 2500 models manufactured. From 1919, it was Georges Friedel (1865-1933), who had been a professor at the École des Mines de Saint-Étienne since 1907, who continued his work but without pursuing any policy of acquisition. In 1932, the 282 model series was created to illustrate the book of Dana and Ford (1932).

Groth has had a major role in the development of crystal model making in Krantz company and, more generally, in the development of crystallography. He continuously cooperated with the Krantz company from the first series of 743 models in 1880. He was the founder and editor (1877-1920) of Zeitschrift für Kristallographie and author of Physikalische Krystallographie und Einleitung in die krystallographische Kenntniss der wichtigsten Substanzen, which appeared in four editions: 1875, 1885, 1895 and 1905 (see Groth, 1905b). Groth was one of the most prolific crystallographers of the time and an avid mediator of the advances of the science of crystallography. He supervised and wrote the foreword to the Krantz crystal model collections: Krantz 743 in 1880; Krantz 213 in 1887; Krantz 88 in catalog 1b 1899, with short descriptions in French of many of the collections; and Krantz 416 in 1905. It is better to refer to the collections as Krantz 743, Krantz 412, etc., rather than to cata$\log$ numbers because some catalogs appeared in several editions, sometimes not bearing a number, and some catalogs are even misnumbered (Johan Kjellman, personal communication, 2021). All the collections and catalogs may be found on the Virtual Museum of the History of Mineralogy site (https://mineralogy.eu, last access: 10 November 2021). Concerning the 416 model, it is a part of the Krantz 416 collection, which was supervised by Paul Groth in 1905 (Groth, 1905a).

In Strasbourg, they do not have a 416 model but, among the 980 wooden models, made by the modeler Wenzel at Krantz, there are some beautiful pieces with a very large number of facets (Denis Leypold, personal communication, 2021). There is no 416 either in the Natural History Museum, London (Robin Hansen, personal communication, 2021). We also contacted the Krantz company in order to know where some other 416 models could be found around the world. Presently, no other one has been found (Ursula MüllerKrantz, personal communication, 2021).

\subsection{Sorting and identification of the models of the École des Mines de Saint-Étienne}

The École des Mines crystal model collection consists in total of more than 400 wooden elements, about 60 terracotta pieces and a series of 30 cardboard sheets. In addition, some 30 different pieces of wood, in the form of short series and varying sizes, are present in the collection, but they are not yet listed.

The 400 wooden models belong to two families. The oldest family is from a series of more than 410 models (the highest number on a model). The school owns 250 of them which have a tracking number. The 416 model probably belongs to the same set. Johan Kjellman (personal communication, 2021) suggested that this series corresponds to the Krantz 416 set. For this series, some 30 cardboard sheets, each with 12 handmade drawings and a description of each model, were found (Fig. 3). Only 3 cards are missing. These cards are not signed, but they probably date from Friedel's time. The last drawing is number 403 . The last cardboard $405-416$ is missing (if it exists). It should have included a description of the 416 model. The cards have been handled by many students and are subsequently no longer easily readable. In addition, their time in the reserves has adversely affected their condition. However, thanks to computer graphics techniques, after scanning and processing images, their copies are now readable. It is from these copies that new labels have been printed for each piece.

Comparing the drawings and samples actually in the collection, we note the absence of about 160 pieces. These deficiencies are probably the cause of the subsequent acquisition of Krantz's parts.

The other series, more recent and less old looking, includes 112 models. The nature of the wood in the two series seems to be different. However, Jean-François Telley, of the Conservatoire des Meilleurs Ouvriers de France (personal communication, 2020), confirmed that all models were 


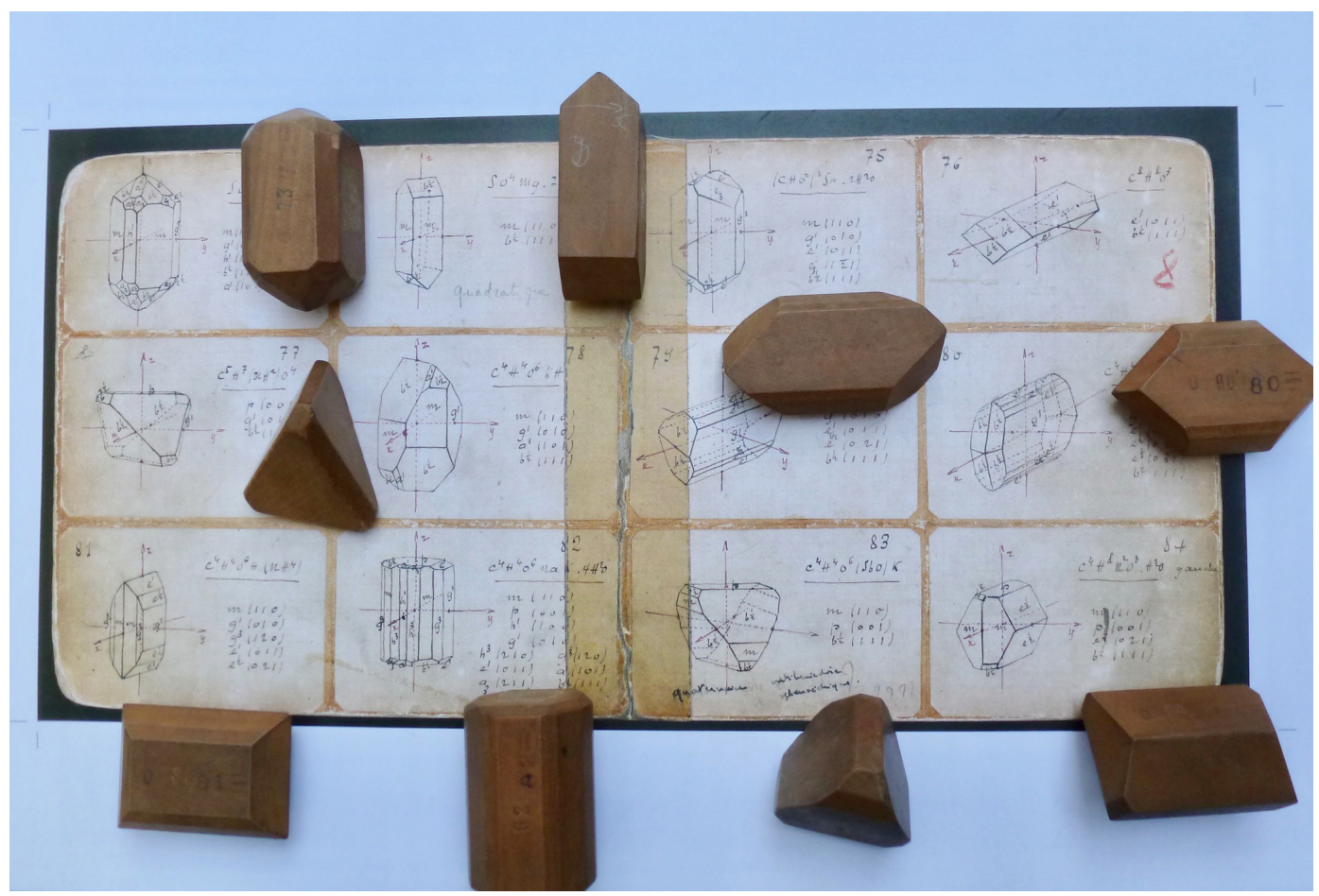

Figure 3. Example of a cardboard sheet $(20 \times 15 \mathrm{~cm})$ with corresponding drawings, indications and models.

made of pear wood, as is mentioned in the Krantz catalog (Birnbaumholz).

After a long search and reaching out to numerous contacts, it was possible to find a correspondence between the samples of the more recent series and those made to illustrate the work of Dana and Ford (1932). The Krantz 282 Dana collection 29, second edition, 1936 catalog was compiled by William E. Ford and was completed by Cornelius S. Hurlbut, Jr., of Harvard University. Thanks to these documents, the 112 Krantz models of the school were identified. The series is composed of 198 models and 84 twins and compounds. The school has only 112 of those 198 models. The highest number is 183 . On all these elements, the logo of the Krantz company is stamped (Fig. 4). After some additional research and discussions with Ursula Müller-Krantz (personal communication, 2021) and Johan Kjellman (personal communication, 2021), it was concluded that these models depict the first appearance of the logo which must have been designed for the 100-year commemoration of the firm in 1933 .

All models are now defined. One may think, although there are some duplicates, that the new Krantz series is complementary to the old one and was purchased to fill the gaps due to lost pieces. Figure 5 shows a case of duplication: on the left is a sample with the logo from the Krantz 282 Dana collection, with its label obtained from the Dana and Ford (1932) book, and, on the right, is the same model from the old series with its label from one of the cardboard sheets (Fig. 5).

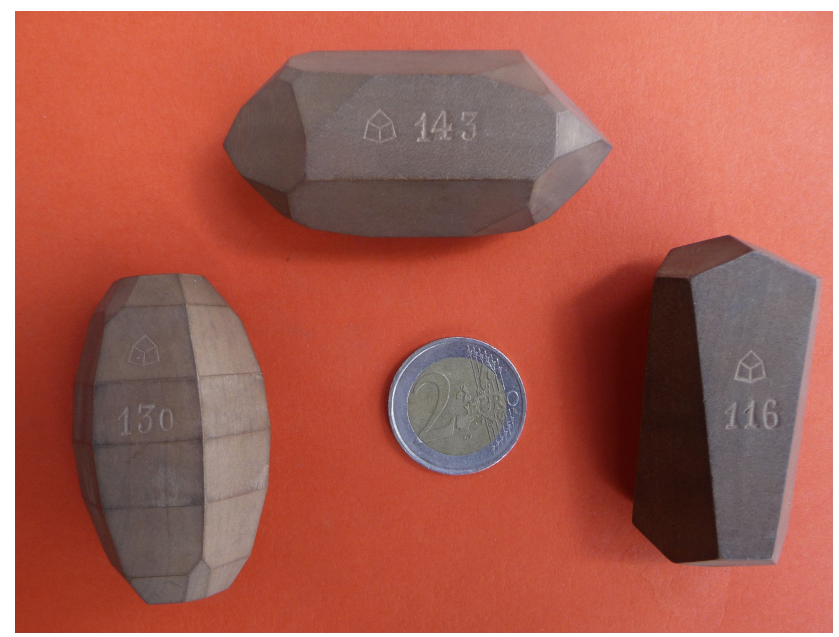

Figure 4. Logo of the Krantz company that can be read on three wooden models (numbers 116, 130, 145) of the École des Mines de Saint-Étienne collection.

All in all, the École des Mines collection of wooden models consist of 250 out of 416 old ones and 112 out of 198 new ones. For presentation, the Krantz recent series models were placed following the old models, for each type of crystalline shape. The labels of the Krantz series were created from the Krantz catalogs and figures from the work of Dana and Ford (1932). 
(a)

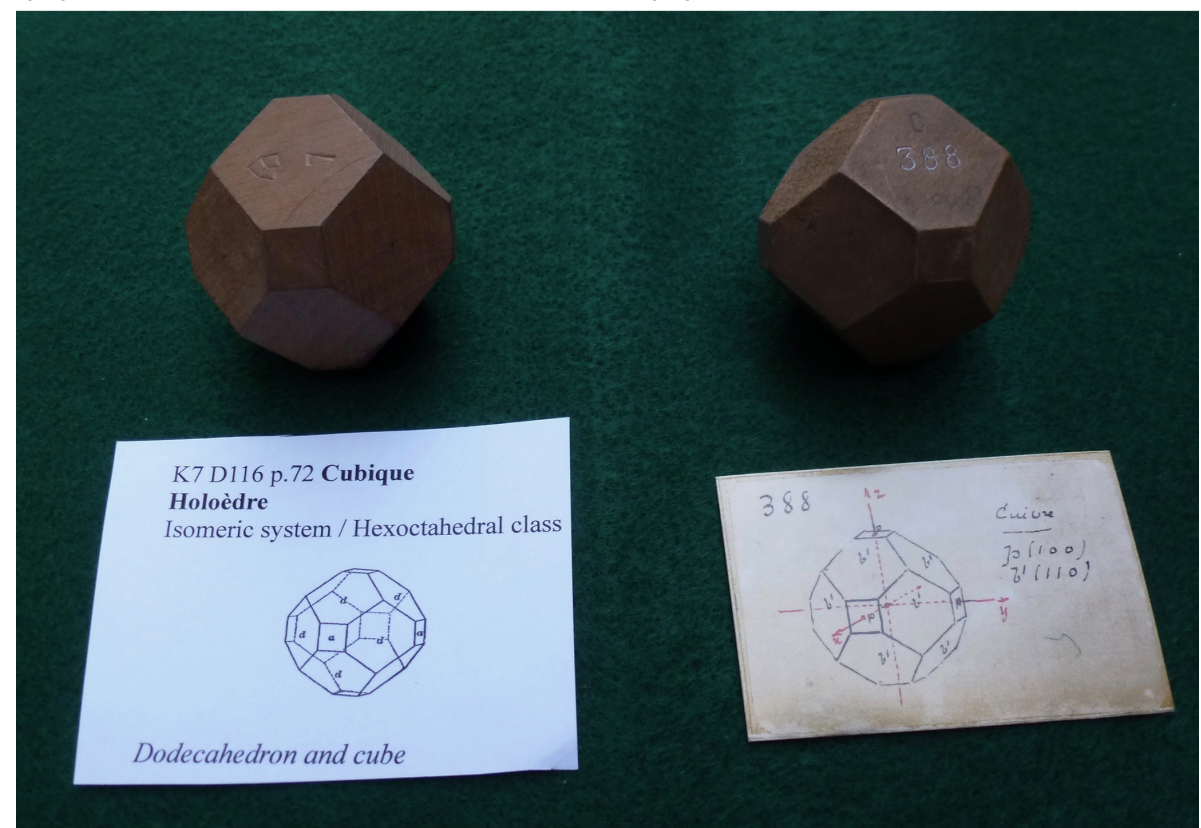

Figure 5. Example of duplication of the same crystallographic model: (a) with the Krantz logo and the label taken from Dana and Ford (1932) and (b) one of the first series with the label taken from the cardboard cards.

\section{Study of cubic model 416}

\subsection{Description}

The most remarkable piece in the collection is the one with number 416 (Fig. 6). It is described in the catalog 6b "Sammlung von 416 Krystal-Modellenin Birnbaumholz", from the Groth (1905a) book. It is noted that "if one (111) facet is placed horizontally and one (100) in front of the observer, the model shows the scalenohedral-ditrigonal combination".

It is a kind of faceted sphere, made of pear wood, that has 170 individual facets of (001) to (123). We do not know how it was made from a single block (if it is - we will check; see Sect. 3.2 below). Its creator certainly used a goniometer because the angles between the facets are accurate. The machining technique is unknown. We assume that the creator started from a cube of wood and that each facet was oriented from the faces of the cube with its calculated angle. However, the distance between a facet and the center of the cube is left to the operator evaluation in order to create the maximum number of facets. The result is that the form has lost a part of its "sphericity".

We do not know why this exceptional piece was made: was it from pedagogic interest or for a technological challenge? However, at the end of the catalog, it is mentioned that this model presents a combination between two systems (Groth, 1905a). Faced with this technical feat dating back 100 years, we have, on the one hand, made the same piece with modern means of digital machining and, on the other hand, had a bronze copy made by precision molding. As a pedagogic exercise, a student was asked to make the calculations and to write the program for digital machining. The reason why we made bronze copies is because the original 416 copy is a unique piece which will be placed in a safe cabinet. Its bronze copies will be at the disposal of students and visitors.

\subsection{A question}

At the beginning of our investigation, we assumed that the original 416 model was machined in a unique block of wood. In order to check that, we used the Siemens SOMATOM Confidence ${ }^{\circledR}$ medical computed tomography scanner at the University Hospital of Saint-Étienne, on both the wooden and the PLA (polylactic acid) models. We knew that X-rays may be useful to investigate the internal structure of woods (Longuetaud et al., 2014). The experiment conditions were $0.6 \mathrm{~mm}$ cuts, $140 \mathrm{kV}$ and $63 \mathrm{~mA}$.

After soft and hard filters and 3D reconstructions and many views at various angles, the images show the interface track between the two halves of the PLA model (Fig. 7). Its shape is a ring because the model is composed of a hard thin layer at the surface and a foamy honeycomb cellular structure inside. In contrast, there is no interface track on the wooden model (Fig. 8). Regular and continuous lines corresponding to the fiber wood structure demonstrate the homogeneity of a unique block of wood in which the model was machined. 


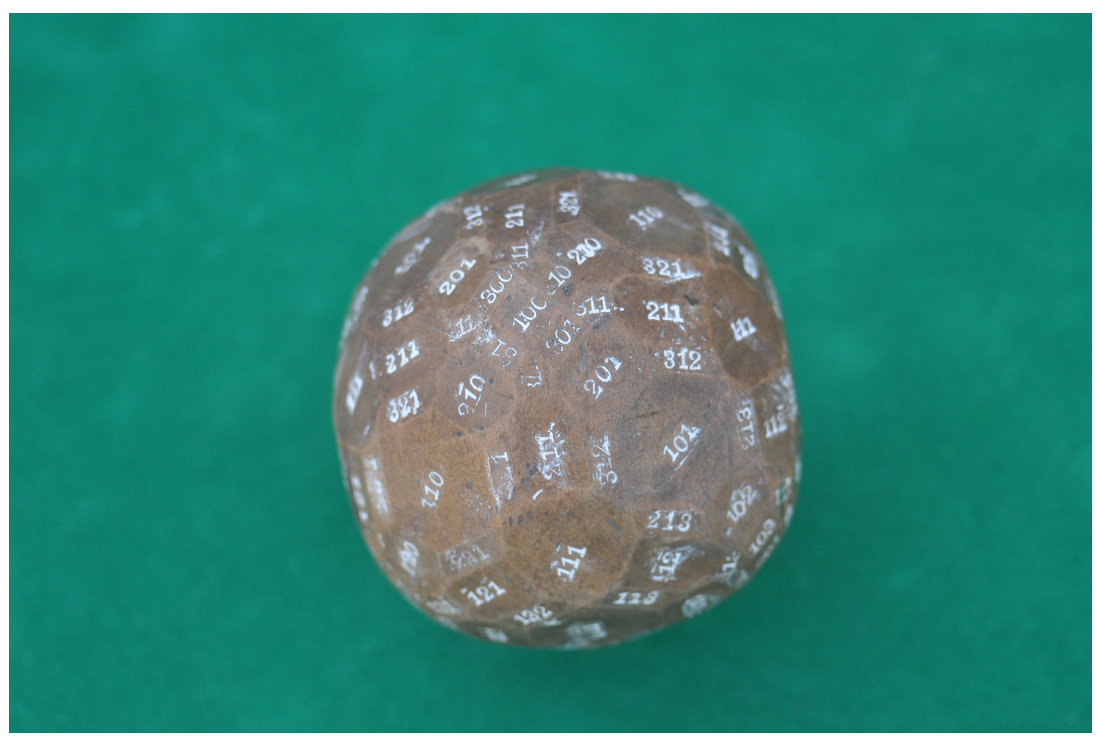

Figure 6. Model 416 with 170 facets. Cubic system. Dimensions $65 \mathrm{~mm}$ between two (001) opposite facets.

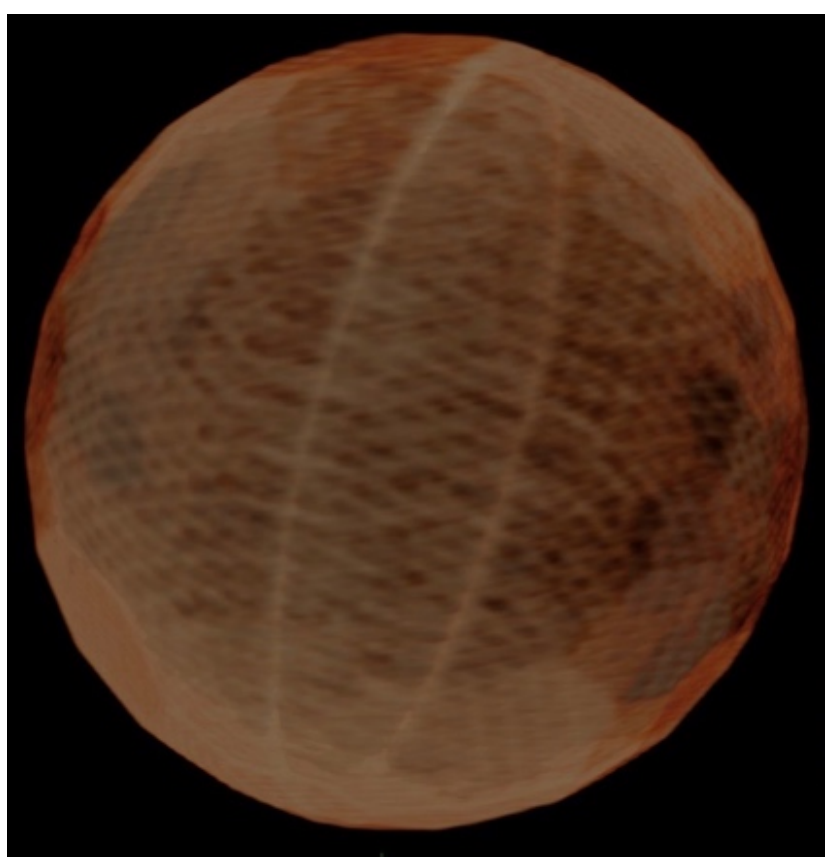

Figure 7. Computed tomography (CT) scan reconstruction of the PLA (polylactic) model. Interface and honeycomb internal structure. Diameter $65 \mathrm{~mm}$.

\section{Creation of new copies}

\subsection{Identification of the $\mathbf{1 7 0}$ facets}

In order to create a digital model, it was necessary to calculate all the angles between 2 by 2 facets. In the cubic system, facets are named from the reference trihedron of the cube faces, with Miller indexes $\{h k l\}$. There exist 6 facets

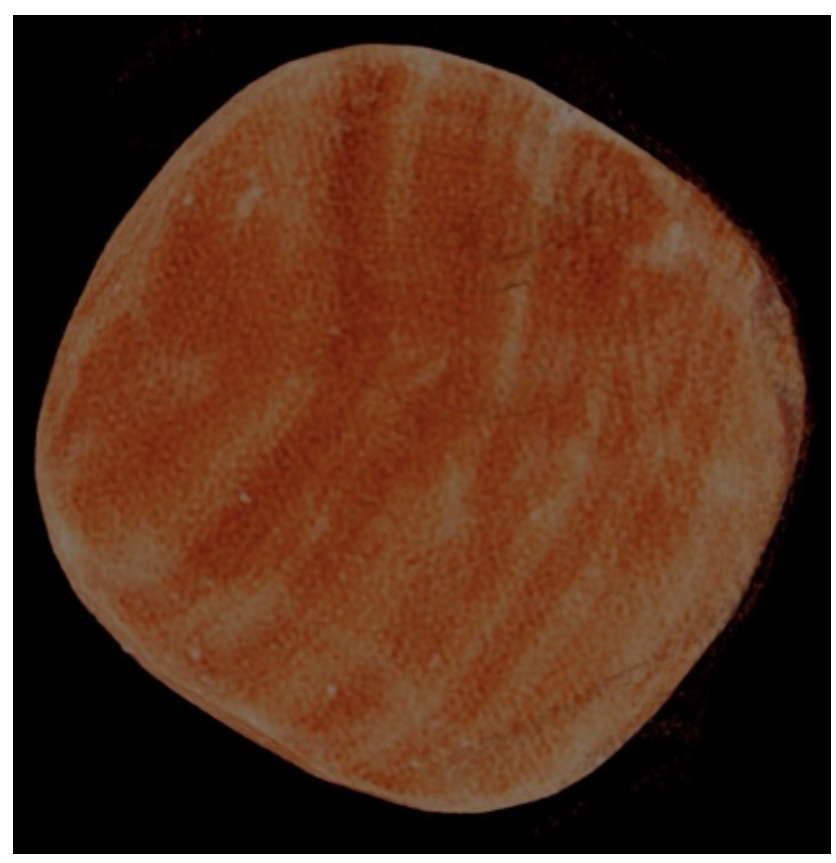

Figure 8. Computed tomography (CT) scan reconstruction of the wooden model. Homogeneity. Largest diameter $65 \mathrm{~mm}$.

corresponding to the cube faces named (100), (010), (001), (100), $(0 \overline{1} 0)$ and $(00 \overline{1})$. There are 12 diagonal facets $\{110\}$ and 8 octahedral facets $\{111\}$. In addition, we number 24 $\{012\}$ facets, $24\{013\}$ facets, $24\{112\}$ facets, $24\{113\}$ facets and $48\{123\}$ facets. In total, there are 170 facets: $6+12+8+24+24+24+24+48=170$. 
The angles $\theta$ between all the facet pairs are calculated using

$\cos \theta=\frac{\boldsymbol{n} \cdot \boldsymbol{n}^{\prime}}{\bar{n} \overline{n^{\prime}}}$,

$\boldsymbol{n} \cdot \boldsymbol{n}^{\prime}=h h^{\prime}+k k^{\prime}+l l^{\prime}$,

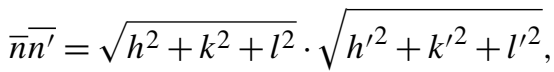

where $\boldsymbol{n}(h, k, l)$ and $\boldsymbol{n}^{\prime}\left(h^{\prime}, k^{\prime}, l^{\prime}\right)$ are the vectors normal to the facets $(h, k, l)$ and $\left(h^{\prime}, k^{\prime}, l^{\prime}\right)$ respectively.

\subsection{Creation of a digital model}

A 3D computer model was first made using the modeling software Rhinoceros 5@ from the Cadlink company in Bordeaux, France. This software is convenient for designers, architects and even for jewelers, giving useful tools for machining or 3D printing from physical models, digital data or technical drawings. It allows a high precision for many kinds of project and is easy to learn, with a relatively low price.

Due to the cubic symmetry of the model, it is enough to study a one-eighth sector of the sphere (only positive indexes) and to duplicate the results for the seven others (Fig. 9). A sphere was cut by all the oriented planes at a variable distance from its center in order to show all the 170 facets. Our optimization produced a regular set just about tangent to a $60 \mathrm{~mm}$ inside virtual sphere.

\subsection{Making a copy by digital machining}

The first method of machining was to make the part in a block of wood. Several options were possible. The faces could have been cut and shaped with hand tool methods, as for the original model. We have not found any technician capable of doing so.

Another method would have been cutting faces with a saw or a milling machine equipped with a goniometer. This method could have provided the necessary precision, but the real difficulty would have been in holding the part on the machine because its holding would have become more and more difficult as the faces were cut.

To get around this difficulty, we considered making the piece in two halves that would be glued together. But having been unable to find access to a five-axis digital mill, we momentarily deferred this idea to make the piece by material removal.

Rather than using a subtractive process, we opted for 3D printing with thermoplastic bioplastic PLA (polylactic acid, a biodegradable polymer obtained from corn starch, with a melting temperature of $175^{\circ} \mathrm{C}$ ), from the numerical model described above, positioning all the facets to delineate a volume included between all these facets. It would have been possible to make the entire piece, but to obtain more precision, it was made in two halves that were assembled by gluing (Fig. 10).

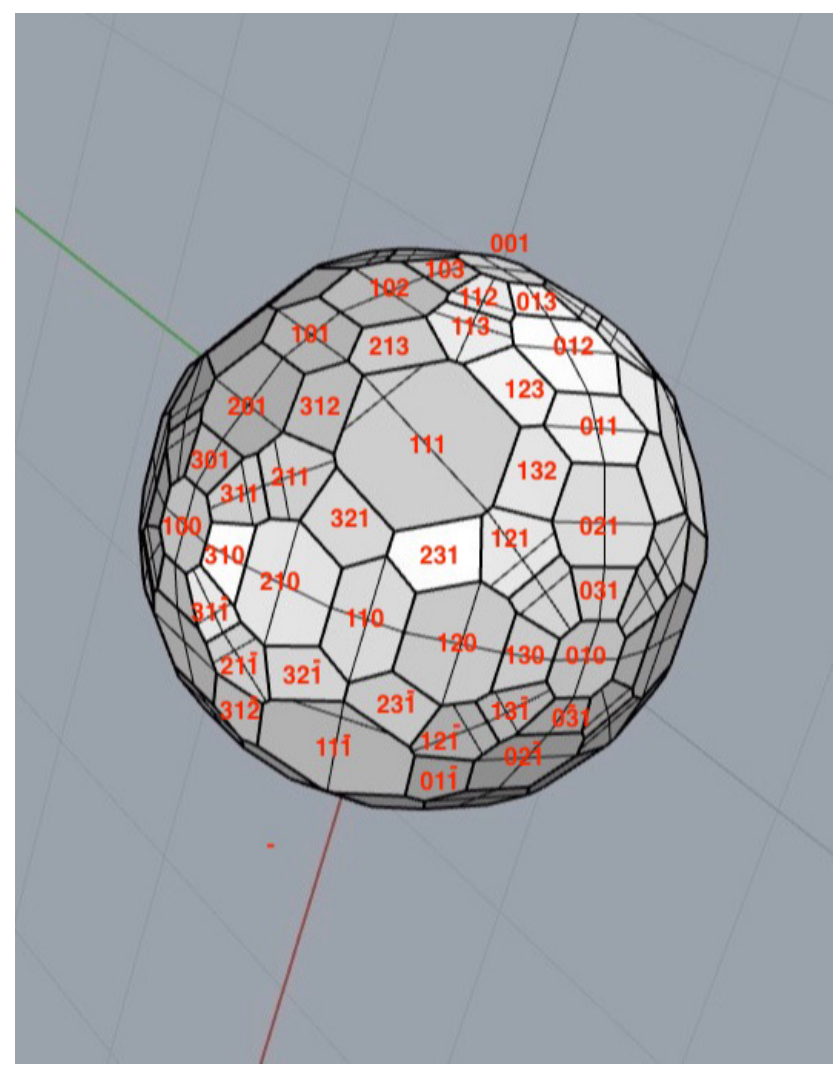

Figure 9. A 3D digital model. Miller indexes were printed on the picture.

The indexes of each facet were printed on transfer paper and glued on the model.

\subsection{Making a copy by precision foundry}

A copy of the model was made by precision foundry using the precision lost-wax vacuum casting technique at Solyfonte in Montbrison (France). The original piece was put in silicone to form a block that was cut to free the piece and leave a void of the shape of the piece. Various holes were made to introduce the wax into the cavity of the block while allowing one to keep only a thin thickness of wax in order to achieve, in the end, a hollow piece, thinner and lighter and with better surface quality than an all-metal one.

The wax piece was equipped with accessories for casting bronze and evacuating air. The whole piece, inside and outside, was covered with refractory material. After heating, the wax, once liquid, was removed and replaced with molten bronze, under vacuum. After removal, specialized finishing operations were carried out to remove the molding accessories, achieving a completely closed hollow casting part and a surface state giving a patinated appearance. Digits in intaglio were filled in with glycerophtalic paint (Fig. 11).

Two pieces were made. Jean Rieu offered one to the École des Mines de Saint-Étienne. 


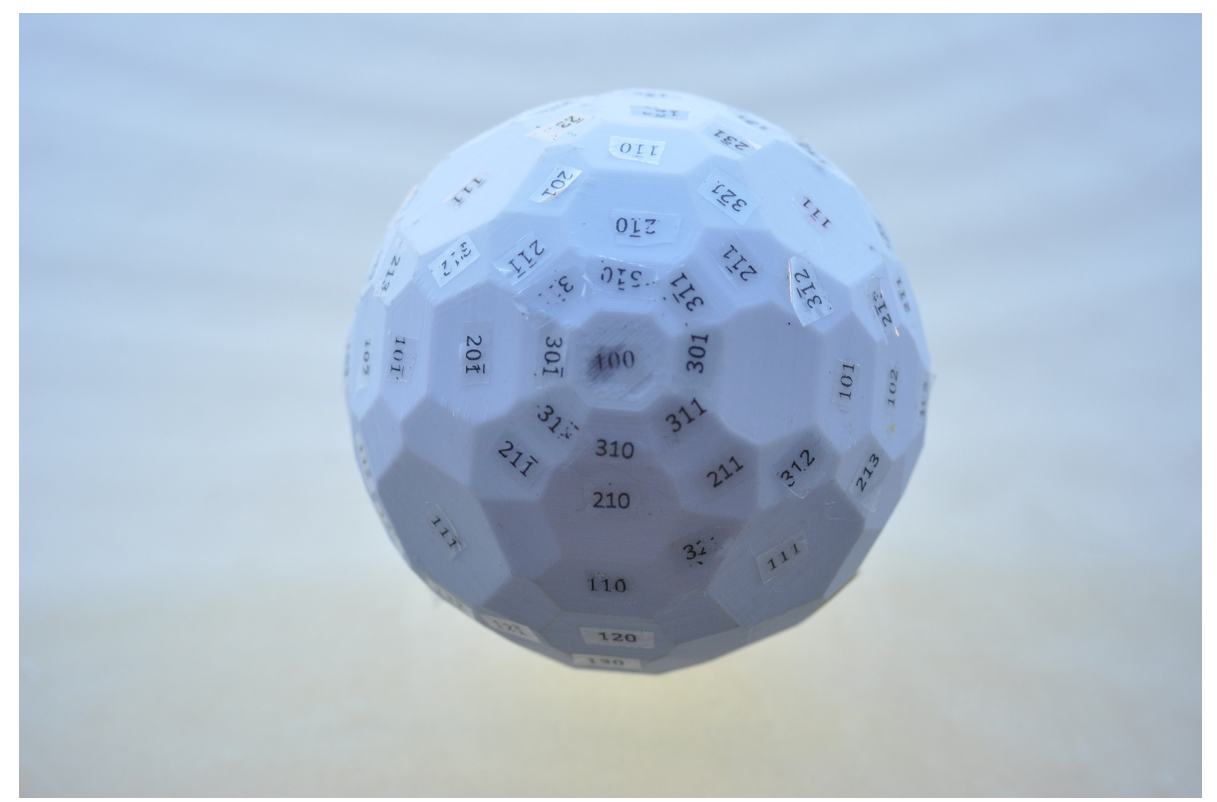

Figure 10. Copy made by 3D printing from the digital model. Diameter $65 \mathrm{~mm}$.

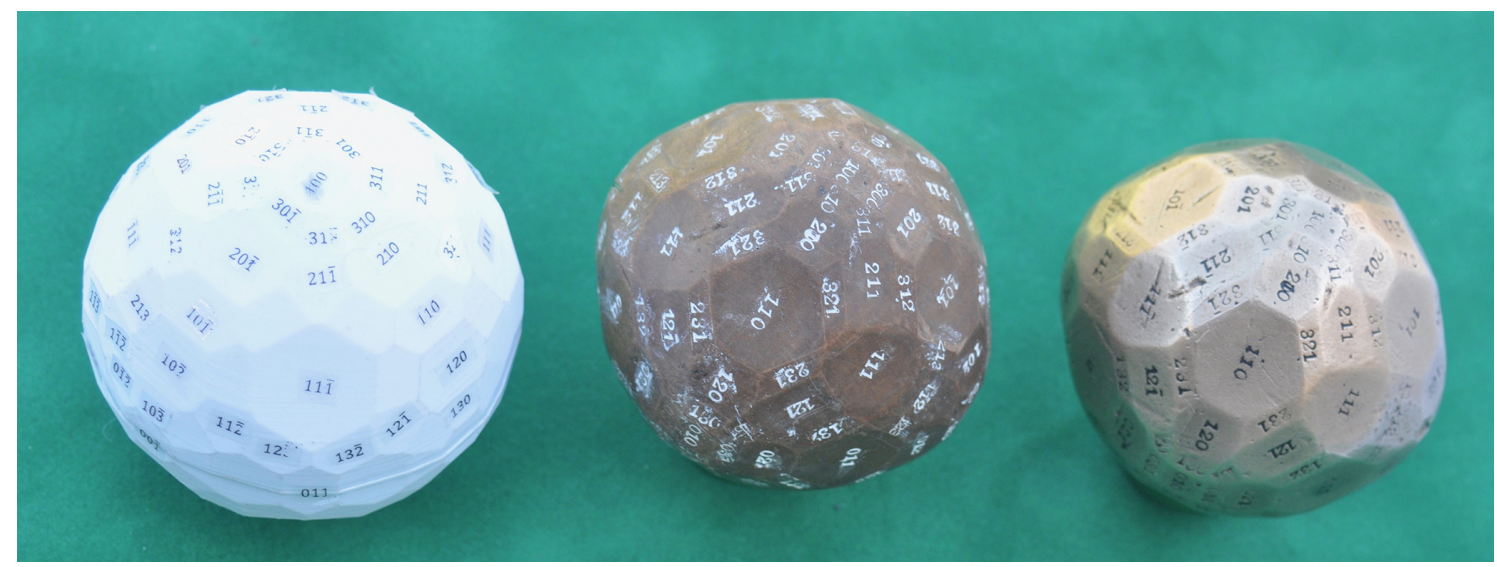

Figure 11. The three models: digital 3D copy (diameter $65 \mathrm{~mm}$ ), original model 416 and bronze copy (65 mm only between two (001) opposite facets).

\section{Conclusion}

Among the more than 400 wooden crystallographic models and a 100-piece collection of terracotta models in the mineralogy collection of the École des Mines de Saint-Étienne, there is one remarkable kind of faceted sphere, made of pear wood, that has 170 individual facets: the 416 model from the Krantz 416 set. We did not know why and how it was machined with the techniques available at the end of the 19th century. Was it more for a technological challenge than for a pedagogic purpose?

The existence of several series of Krantz models was identified by logos and linked to catalogs. The important work of Groth on these models, in cooperation with the Krantz company, was highlighted. After describing the whole collection of the wooden models, we analyzed the 416 model and reproduced it by modern means of digital machining and precision art lost-wax vacuum casting. We could not produce a single block piece by digital machining and had to make it in two halves that were glued together. Computed tomography scanning on both the polymeric sample and the 416 model allows us to prove that the wooden model was machined in a unique block of wood. This enhances the idea of the technical prowess of its author.

Our wish would be that this unique piece and the whole collection of crystallographic models are better known and appreciated. The École des Mines de Saint-Étienne's model 416 might very well be the one and only piece of its kind around the world; who knows? 
Code availability. Rhinoceros software is purchased from the company Cadlink in Bordeaux (France): http://rhino3d.com (McNeel and Associates, 2021).

Data availability. All the collections and catalogs may be found on the Virtual Museum of the History of Mineralogy site (https: //mineralogy.eu, last access: 10 November 2021). Concerning the 416 model, it is a part of the Krantz 416 collection, which was supervised by Paul Groth in 1905 (https://www.mineralogy.eu/ archive/Krantz/Krantz_6b.pdf, Groth, 1905a).

Author contributions. JR did the main part of the work presented in the paper. BG, professor of geology at the École des Mines, was in charge of the mission of safeguarding; he entrusted JR with the collection of crystallographic wooden models, containing memories of JR's distant studies under the direction of Louis Neltner (19031985). BG revised, edited and prepared the manuscript for journal submission. VB, student at the ENSA Paris-La Villette school of architecture and the École Spéciale des Travaux Publics (ESTP Paris), Cachan, did the computer modeling of the 416 sample and helped translate the text from French to English. Some of his work was done while studying at Aalto University in Finland.

Competing interests. The contact author has declared that neither they nor their co-authors have any competing interests.

Disclaimer. Publisher's note: Copernicus Publications remains neutral with regard to jurisdictional claims in published maps and institutional affiliations.

Acknowledgements. We thank the anonymous reviewers, whose comments helped enhance the quality of the manuscript; we thank all the people with whom we could discuss the issues related to our paper. Our deepest appreciation goes to Philippe Jamet, director of the École des Mines de Saint-Étienne, who realized the heritage value of the collections and who decided to restore them. Pascal Ray, current director of the school, shares this concern for safeguarding the collections, as do David Delafosse, Jean-Michel Herri and Ana Cameirao in the École des Mines. We thank the entire team of geologists and mineralogists (Jean-Luc Bouchardon and Jacques Moutte) who helped us and gave us valuable information; Marc Doumas helped us in finding the Dana and Ford (1932) book and provided interesting comments. Our work on models is nothing compared to the immense and remarkable work undertaken on minerals and rocks by Yves Masson, Jean Chalier and Michel Pouzadoux. Our thanks go to Johan Kjellman, from the Museum of Evolution, in Uppsala, and from the Oryctics group, who gave us the reference of the Krantz 416 set catalog and provided many interesting comments. He helped us to make corrections in our text with regards to complementary information and better presentation. We thank Ursula Müller-Krantz for the information she gave us about the models of the Krantz company; Denis Leypold for the information he gave us about the Strasbourg collection; Robin Hansen for the information about the Natural History Mu- seum, London; and Jean-François Telley, of the Conservatoire des Meilleurs Ouvriers de France, for the information about the wood used for the models. We are indebted to Paul Heinrich von Groth and to the Krantz company for having created so many useful crystal models in order to demonstrate all the possible facets in crystallographic systems. During many years, students had powerful aids to visualize and understand crystallography. We thank Vincent Rieu and his team at the Brailly printing plant in Saint-Genis-Laval for digitizing and processing images from the old catalog and printing labels. Thanks also go to our correspondents who helped us find the references of the Krantz samples: Frantz Krantz, from Krantz in Bonn; Lydie Touret, from the École des Mines de Paris; Joan Abelle i Crreu, from Barcelona; and Claude Hootelé, from Brussels. We thank Christophe Saint-Romain of the Solyfonte company for the production of precision casts and Fréderic Farizon, who introduced us to Sylvain Grange and his team of the University Hospital of Saint-Étienne. Many thanks go to those who performed the scanner investigations on the models. We thank Hélène Rieu-Isaacs and Ron Isaacs for their help given to Victor Beley in reviewing the English version of this paper.

Our wish would be that this collection is better known and appreciated so that the models regain their pedagogical character for the teaching of crystallography. Having a tool of such scientific, aesthetic and historical value should encourage a better understanding of the nature of natural crystals whose beauty is no longer to be demonstrated.

This work is dedicated to Louis Neltner, one of the greatest directors of the École des Mines de Saint-Étienne. Not only did he initiate us in crystallography, but he gave us a taste for research and teaching and a love for mountains and alpinism. A thought also for Jacques Lévy (1937-2012), who used wooden models in his teaching of crystallography. He left before he saw our collection refurbished.

Review statement. This paper was edited by Cristiano Ferraris and reviewed by two anonymous referees.

\section{References}

Dana, E. S. and Ford, W. E.: A Textbook of Mineralogy with Extended Treatise on Crystallography and Physical Mineralogy, 4th edn., John Wiley \& Sons, ISBN-13 9780471193050, ISBN$100471193054,1932$.

Groth, P.: Sammlung von 416 Krystall-Modellen in Birnbaumholz, Krantz, F., Rheinische Mineralien Contor, Bonn, available at: https://www.mineralogy.eu/archive/Krantz/Krantz 6b.pdf (last access: 10 November 2021), 1905a.

Groth, P.: Physikalisches Krystallographie, Leipzig, Verlag von Wilhelm Engelmann, 1905b.

Haüy, A. R. J.: Essai d'une théorie sur la structure des crystaux, Éd. 1784 de René-Just Haüy, Éditeur: Hachette Livre BNF (1 mai 2012), 250 pp., ISBN-10 2012542840, ISBN-13 9782012542846, 1784 (in French).

Haüy, A. R. J.: Exposition abrégée de la théorie sur la structure des crystaux, Éd. 1792 de René-Just Haüy, Éditeur: Hachette Livre BNF (1 janvier 2012), 55 pp., ISBN-10 2012663265, ISBN13 978-2012663268, 1792 (in French). 
Insley, J.: Crystal Clear! Crystal Models in the Natural Science Collections at the National Museums Scotland, Bulletin of the Scientific Instrument Society, 125, 38-43, 2012.

Kjellman, J., Heide, B., and Heide, G.: On the historical crystal model sets in the mineral collections of Abraham Gottlob Werner on the TU Bergakademie Freiberg, in: Kandler S.: Abraham Gottlob Werner und die Geowissenschaften seiner Zeit: Zum 200. Todestag des Geologen, Mineralogen und Montanwissenschafters: ausgewälte Vorträger des Internationalen Werner-Symposiums vom 29. Juni bis 1. Juli 2017, Freiberger Foschungshefte, D 250, 149-179, 2020.

Longuetaud, F., Mothe, F., Santenoise, P., Colin, F., Borianne, P., and Deleuze, C.: Un scanner tomographique à rayons $\mathrm{X}$ pour l'analyse de la structure interne des arbres, Rendez-vous Techniques de l'Office National des Forêts, 57-64 and <hal01837381>, 2014 (in French).

McNeel, R. and Associates: Rhinoceros 7, http://rhino3d.com, last access: 5 June 2021.
Romé de l'Isle, J.-B. L.: Cristallographie, ou description des formes propres à tous les corps du règne minéral, dans l'état de combinaison saline, pierreuse ou métallique, Imprimerie de Monsieur, Paris, 1783 (in French).

Tandy, P.: Crystallography and the geometric modelling of minerals: a reflection on the models in the Natural History Museum, London, The Geological Curator, 6, 333-338, 1998.

Touret, L.: Un rare exemple de cabinet du XVIIIème siècle: le cabinet des fossiles au Musée Teyler de Haarlem (Pays-Bas), Travaux du Comité Français d'Histoire de la Géologie, available at: http: //www.annales.org/archives/cofrhigeo/cabinet-19eme.html (last access: 10 November 2021), 1991.

Wilson, W. and Kjellman, J.: Nathaniel Larkin (1781-1855) and John Richard Larkin (1818-1876): Early Crystal Model Makers, The Mineral Record, 46, 269-276, 2015. 